\title{
Participação social e as audiências públicas do plano diretor - mito ou verdade?
}

\author{
Social Participation and Master Plan Public Hearing - myth or truth? \\ Participación social y audiencias públicas del plan maestro - ¿mito o verdad?
}

Recebido: 08/07/2021 | Revisado: 12/07/2021 | Aceito: 14/07/2021 | Publicado: 24/07/2021

\author{
Bruna de Souza Santos \\ ORCID: https://orcid.org/0000-0003-1527-7291 \\ Universidade Salvador, Brasil \\ E-mail: bruna1010@hotmail.com \\ Ana Licks Almeida Silva \\ ORCID: https://orcid.org/0000-0003-1711-4728 \\ Universidade Salvador, Brasil \\ E-mail: ana.almeida@unifacs.br
}

\begin{abstract}
Resumo
O presente artigo tem como objetivo analisar a participação popular no que diz respeito aos planos diretores, trazendo como exemplo o Plano Diretor de Desenvolvimento Urbano (PDDU) de Salvador, na Bahia. Seu propósito é correlacionar a participação social das audiências públicas na efetivação do instrumento ZEIS com os efeitos da segregação socioespacial, analisando suas complexas relações no espaço e sociedade. A discussão é voltada para a análise das posições sociais e o espaço, seus impasses na questão da apropriação e nas suas interações. Deste modo, é possível investigar a eficácia da participação popular e as possibilidades de restituição do cenário social, tornando evidente problemáticas que envolvem os movimentos sociais. A metodologia de trabalho consiste em consultas bibliográficas, análise de documentos oficiais (como as atas das audiências públicas realizadas pela Prefeitura) e entrevistas com atores sociais de entidades e movimentos sociais que participaram da discussão do PDDU.
\end{abstract}

Palavras-chave: Participação social; Audiências públicas; ZEIS.

\begin{abstract}
This article aims to analyze popular participation about the Urban Development Master Plan (PDDU) of Salvador, Bahia. It is purpose is to correlate the social participation of public hearings in the implementation of the ZEIS instrument with the effects of socio-spatial segregation, analyzing it is complex relationships in space and society. The discussion is focused on the analysis of social positions and space, their impasses in the question of appropriation and in their interactions. In this way, it is possible to investigate the effectiveness of popular participation and the possibilities of restoring the social scene, making evident the problems that involve social movements. The work methodology consists of bibliographic consultations, analysis of official documents (such as the minutes of public hearings held by the City Hall) and interviews with social actors from social organizations and movements that participated in the PDDU discussion.
\end{abstract}

Keywords: Social Participation; Public hearings; ZEIS.

\section{Resumen}

Este artículo tiene como objetivo analizar la participación popular en los planes maestros, tomando como ejemplo el Plan Maestro de Desarrollo Urbano (PDDU) de Salvador, Bahía. Su propósito es correlacionar la participación social de las audiencias públicas en la implementación del instrumento ZEIS con los efectos de la segregación socioespacial, analizando sus complejas relaciones en el espacio y la sociedad. La discusión se centra en el análisis de las posiciones sociales y el espacio, sus impasses en el tema de la apropiación y en sus interacciones. De esta manera, es posible investigar la efectividad de la participación popular y las posibilidades de restitución del escenario social, evidenciando problemas que involucran a los movimientos sociales. La metodología de trabajo consiste en consultas bibliográficas, análisis de documentos oficiales (como las actas de audiencias públicas realizadas por el Ayuntamiento) y entrevistas a actores sociales de organizaciones y movimientos sociales que participaron en la discusión del PDDU.

Palabras clave: Participación social; Audiencias públicas; ZEIS.

\section{Introdução}

O presente artigo tem como objetivo analisar a efetividade das audiências públicas enquanto instrumentos de participação popular na elaboração dos planos diretores, especificamente na cidade de Salvador. 
Dado que essa modalidade de participação, prevista no Estatuto da cidade, confere legitimidade aos grupos sociais de defenderem, democraticamente, seus interesses, no que diz respeito às políticas públicas urbanas, garantindo-lhes o direito à cidade, é mister reconhecer que sua efetividade está associada a uma gama de variáveis que devem ser analisadas conjuntamente. Entende-se a efetividade como produto da eficácia (atingir os objetivos) e da eficiência (fazê-lo da melhor forma possível).

A desigualdade que impera nas múltiplas esferas - social, econômica, política, cultural e ambiental, acaba por refletirse nesse processo participativo, imprimindo-lhe fragilidade e desequilíbrio de forças. Compreender como se estabelece e se define esse processo participativo é questão basilar, que contribuirá para o amadurecimento e aperfeiçoamento das formas democráticas de participação.

Com esse intuito, buscamos na literatura autores que abordam essas questões, além de analisarmos documentos que contenham as premissas sobre o modelo de audiências públicas utilizadas ao longo da última década (2010) no processo de elaboração dos planos diretores, com ressalvas ao Plano Diretor de Desenvolvimento Urbano do município de Salvador/BA.

Refinando ainda mais esse propósito, nos concentraremos nas audiências que envolvem a elaboração de parâmetros para as Zonas Especiais de Interesse Social (ZEIS), bem como sua regulamentação, dado que em Salvador, cerca de $20 \%$ do seu território são ocupadas por essas unidades territoriais (Ibge, 2010). Ademais, algumas delas se inserem em áreas ambientalmente valorizadas, outras conflitam com usos institucionais e outras, ainda, são limítrofes a bairros onde moram a elite soteropolitana.

A população residente das ZEIS, que representa mais de 50\% da população de Salvador, $81 \%$ preta, com renda média mensal de $\mathrm{R} \$ 973,00$ e uma média de $68 \%$ das pessoas com mais de 25 anos, com o ensino fundamental completo, vive uma permanente tensão, ainda que latente, sobre seu território (Ibge, 2010).

A especulação imobiliária, a violência, o desemprego e a marginalização social são mais que fantasmas e fazem parte do cotidiano dessas pessoas. Pergunta-se, portanto, diante desse cenário, como é possível garantir que esse grupo e seus representantes sejam ouvidos? Como garantir a participação social efetiva a essa parcela da população?

Com o objetivo explícito de mudança neste cenário, a Constituição Federal de 1988 demarca no Artigo 182 a função social da propriedade, regulamentado pelo Estatuto da Cidade que, por sua vez, dispõe sobre o direito à cidade (Lei $n^{\circ}$ 10.257/2001) e garante a implementação das ZEIS.

Instrumento de política urbana/habitacional, a ZEIS nasceu na década de 1980, fase de redemocratização do país, por disposição de específicos governos brasileiros que apoiavam movimentos de moradia e, consequentemente, pesquisavam formas de aliar a infraestrutura nas favelas com a legislação brasileira como forma de assegurar seus direitos. Constituída como instituto político e jurídico, as ZEIS são definidas na Lei n ${ }^{\circ} 11.977$ de $2009^{1}$ como

[...] parcela de área urbana instituída pelo Plano Diretor ou definida por outra lei municipal, destinada predominantemente à moradia de população de baixa renda e sujeita a regras específicas de parcelamento, uso e ocupação do solo" (art. $\left.4^{\circ}, \mathrm{V}, \mathrm{f}\right)$.

As ZEIS objetivam, portanto, o reconhecimento da pluralidade de ocupações existentes, promovendo a incorporação da cidade informal à formal, além de garantir a função social da propriedade, ao orientar o uso da terra urbana e/ ou edificações comprovadamente ociosas, para fins sociais. Enseja ainda segurança jurídica, amplificação da oferta de terras para a realização de Habitações de Interesse Social (HIS); define parâmetros específicos urbanísticos para as áreas em questão; promove a participação popular na partilha de recursos públicos e resoluções administrativas.

${ }^{1}$ Tal lei situou as normas básicas do Programa Minha Casa Minha Vida, além de auxiliar avanços jurídicos para a política nacional de integração urbana de assentamentos precários (Ancona, 2017). 
Cabe ao município estabelecer diretrizes e regras gerais para a aplicação das ZEIS por meio do Plano Diretor e das leis complementares, já que se trata de um instrumento de zoneamento. Embora a elaboração técnica de instrumentos urbanísticos como as ZEIS esteja a cargo de profissionais, a participação popular é garantida por ocasião da realização das audiências públicas, etapa imprescindível e mandatória ao processo de elaboração dos planos diretores.

São muitos, porém, os fatores que influenciam esse processo participativo, que envolve desde as convocações para as audiências até a representação dos diversos grupos sociais na defesa dos seus interesses. Esses fatores contribuem diretamente na qualidade dos resultados, uma vez que os técnicos fazem interpretações imprecisas sobre a realidade da comunidade, provocando inúmeras consequências.

Com isso, parte-se para a tentativa de explicação de um dos canais de participação que é o foco dessa pesquisa: as audiências públicas. Extensamente mencionadas nas legislações, a audiência é tida como uma das principais estratégias de participação popular na gestão democrática na cidade, não podendo ser admitidas como meras formalidades (Hermany; Frantz, 2010).

Para alcançar os objetivos previstos nessa pesquisa, foram efetuadas análises dos planos diretores e outros instrumentos de controle urbanístico de Salvador/BA, que permitiam a elaboração de um sistema de avaliação das participações sociais, resultando nas análises de seus impactos descritas mais à frente. O estudo se pauta, sobretudo, em trabalhos de autores como Maricato (2000), Villaça (2001), Foucault (1981), Hermany e Frantz (2010), entre outros, para tecer considerações críticas sobre este processo.

\section{Metodologia}

No que se refere aos procedimentos metodológicos, buscou-se trabalhar com revisão bibliográfica, análises de documentos oficiais (como atas, relatórios e áudios das audiências públicas efetivadas pela Prefeitura), artigos científicos e publicações que abordam tal temática. Em termos da organização das informações, ressalta-se que além desta introdução e da conclusão, o presente artigo encontra-se dividido em duas partes.

$\mathrm{Na}$ primeira, descreve-se a relação das audiências públicas com o histórico da participação social em geral. Na segunda, apresenta-se uma análise da aplicação da Escada de Participação Cidadã (Arnstein, 1969) nas audiências públicas do PDDU de Salvador, cidade exemplo de como relacionar a participação em contextos autoritários e conservadores.

O presente trabalho, portanto, desdobra-se na análise qualitativa da participação popular por meio de dimensões que consideram aspectos relativos à efetividade desse mecanismo. De acordo com Pereira et al. (2018), o método qualitativo dá lugar à interpretação do pesquisador, priorizando as análises qualitativas como coleta de dados. Pautado na revisão bibliográfica e na pesquisa documental, o artigo busca construir um referencial acerca dos assuntos estudados.

\section{A Relação das Audiências Públicas com o Histórico Participativo}

O surgimento da participação popular no planejamento urbano ocorreu com iniciativas norte-americanas e europeias no final da década de 1960 e no início da década de 1970 (Fainstein, 2000; Horelli, 2002). No Brasil, as novas normas da política urbana tornaram obrigatória a participação dos cidadãos no processo de produção de planos diretores municipais, que passou a ser considerado como instrumento básico da política nacional de desenvolvimento urbano.

O planejamento urbano consiste no processo de trabalho permanente, que tem como objetivo a organização sistemática dos meios necessários a serem utilizados a fim de contribuir na melhoria da qualidade de vida urbana e da sociedade. Para isso, é preciso conhecer a realidade local, se aprofundar nas reais necessidades da comunidade para que de fato haja mudanças (Ferrari Júnior, 2004). 
Foucault (1981) defende o planejamento urbano como mecanismo de garantia do lucro, e, como consequência, de poder. Esses mecanismos estão presentes em todas as relações humanas e atualizadas com objetivo de garantir a manutenção do exercício de poder sob quem está exercendo-o.

Baseado nisso, Reinau e Hansen (2006) defende que a forma mais comum para o envolvimento da comunidade são as reuniões presenciais, onde os projetos e suas implicações são indicadas e debatidas. No entanto, sua efetividade é questionada a partir do pressuposto em que a comunidade é apenas informada de um processo já em desenvolvimento, desconsiderando as possíveis opiniões e sugestões dos cidadãos.

A participação não se resume em quando só se toma parte, mas de que forma se faz isso. Tal pensamento se relaciona diretamente ao engajamento nas mobilizações de recursos, fiscalizações nas ações e implementações de políticas públicas que atenda o interesse da maioria da população (Bordenave, 1994).

Sendo assim, a participação pode ser definida como um instrumento fundamental no sentido de promover a articulação entre os atores sociais, fortalecendo a coesão da comunidade e melhorando a qualidade das decisões, tornando mais fácil atingir objetivos comuns. Todavia, é útil advertir que os métodos participativos não podem ser vistos como infalíveis e capazes de solucionar adequadamente todos os tipos de problemas (Medeiros; Borges 2007 apud Manfredini; Lopes, 2005).

O propósito da participação é permitir o contato mais direto e habitual entre a sociedade e as instituições públicas, a fim de proporcionar à ambas a consideração de seus interesses nos processos de tomadas de decisões. Desta forma, há o envolvimento de uma participação ativa da comunidade nas deliberações públicas, na dinâmica do seu território e nos contextos de interesses do todo (Medeiros; Borges, 2007).

Críticas relacionadas aos processos participativos são comuns, a ponto de ser corriqueira sua relação com a ineficácia. Isso ocorre, de certa forma, devido a utilização do termo participação pública, de forma indiscriminada, à diversos métodos diferentes com respectivos níveis de participação (Bugs; Reis, 2014).

Ademais, percebe-se diferenças de acordo com os diversos grupos de cidadãos participantes referentes ao engajamento de cada nos processos. É perceptível o alcance limitado das audiências públicas, atingindo apenas níveis elementares de participação, de consulta e informação.

Tais audiências públicas são estratégias participativas de cunho presencial, abertas ao público, de caráter consultivo e com a possibilidade de manifestação oral dos participantes. Tem como intuito contribuir nas decisões governamentais (Brasil, 2014). Teoricamente, são através delas que se garante o direito dos cidadãos de serem ouvidos, expressarem suas preocupações e reivindicações de forma legítima sobre assuntos que envolvem toda a comunidade. Tal fato, transforma diretamente o instrumento em jurídico-político, englobando várias esferas administrativas e evidenciando sua importância no contexto social.

No entanto, o público desconsidera sua participação como diferenciador nas tomadas de decisões, já que foi apenas informado das ações promulgadas, avaliando o impacto de sua participação como irrisório. Essa situação remete ao caso de processos participativos nos quais apenas autenticam os resultados, informando à população a decisão precedente e solicitando opiniões que possivelmente não serão levadas em conta (Reinau; Hansen, 2006).

O nível de engajamento pelos planos diretores é possivelmente um reflexo da deficiência de mobilização do público. Tal questão contribui diretamente na participação dos cidadãos de acordo com sua identificação nos assuntos tratados, justificando a ausência da participação por não se dizer respeito aos problemas cotidianos da comunidade.

Por fazerem parte da elaboração ${ }^{2}$ dos planos diretores, essas audiências ocorrem a partir da divulgação do calendário das reuniões em sites oficiais da cidade, permitindo a participação de instituições públicas, organizações não governamentais,

2 Tais audiências só são de cunho obrigatório para a elaboração do Plano Diretor, sendo dispensáveis em casos de alterações ou revisão do plano. Sua justificativa se dá pela área de impacto e, consequentemente, pelo número de pessoas que sofrerão as repercussões (Art. 40, Lei 10.257/2001). 
autoridades e associações representativas de diversos eixos da sociedade. As inscrições dos participantes se dão pelo preenchimento de formulários disponíveis no local das audiências e suas participações são registradas em listas de presenças.

Antes de serem realizadas, as audiências precisam ter hora e local pré-definidos, bem como as pautas, atas e outros documentos pertinentes. A condução da reunião também deve ser pré-estabelecida, determinando quais atores possuirão as palavras, o tempo de fala, como a opinião dos participantes serão orientadas e de quais formas serão incorporadas as demandas na política.

Questionamentos e esclarecimentos de dúvidas, bem como sugestões, são fichados através de um formulário próprio presente no local ou por meio digital (ficha eletrônica). Além disso, as críticas e propostas são identificadas e registradas a fim de contribuir no seu processamento e na própria sistematização, já que elas possuem o registro do solicitante - bem como sua demanda - para que a etapa seguinte seja a devolutiva sobre o que foi acertado ou rejeitado.

A infraestrutura é um fator influente direto, uma vez que para que a participação seja efetiva, o local deva suportar confortavelmente os participantes, além de ter fácil acesso. Nas audiências, as mesas são compostas geralmente pelo presidente da Câmara Municipal da cidade ou autoridade qualificada por ele, além de secretários, vereadores, coordenadores de comissões e etc. A participação popular é reconhecida quando a prioridade é ouvir os cidadãos, e, em seguida, os vereadores.

Geralmente é seguido um roteiro onde se inicia com a abertura solene e composição da mesa, bem como a divulgação de informações gerais e a dinâmica da reunião. Após isso, a audiência se desenvolve com os encaminhamentos finais, seu encerramento e o registro das ocorrências em atas circunstanciadas. Esse modelo padrão se torna factível para qualquer cidade, podendo ser feitas alterações para adequação da sistemática nos locais.

Ainda assim, não é possível afirmar que há uma participação significativa da sociedade nas audiências públicas, o que resulta na pouca representatividade. Poucas pessoas possuem o conhecimento de onde achar as informações sobre as reuniões, além de serem pouco divulgados. Outrossim, o mecanismo não consegue contemplar os procedimentos efetivos de diálogo, além de exigir uma linguagem formal que repele o envolvimento da sociedade civil.

Toda a escala de discussões idealizada pelos processos não contempla de fato a representatividade das associações dos bairros presentes. As audiências agem com uma metodologia sinuosa, não facilitando a participação social ao se dedicar, quase de forma exclusiva, às apresentações de estudos técnicos, o que reduz o tempo para a exposição de propostas.

Além disso, é comum o sentimento de desrespeito da população participante com as decisões tomadas pelas prefeituras, uma vez que acordos são feitos nas audiências e descumpridos ao oficializarem as sentenças. $\mathrm{O}$ fato das audiências serem realizadas no mesmo local também indaga os participantes, que questionam a acessibilidade e inclusão do local em bairros específicos. Tal questão pode influenciar no número de participantes, aumentando a participação social e diminuindo consideravelmente o número de audiências.

Não suficiente, ainda há o despreparo na difusão das informações, bem como na interpretação destas devido à falta de entendimento técnico. A desconsideração dos aspectos cognitivos pode ser um dos responsáveis pela inefetividade dos processos participativos. Além disso, ainda há a carência de estudos de cognição humana, bem como seus reflexos em usos de mapas, que auxiliariam o entendimento e, desta forma, o engajamento dos cidadãos.

Outra questão que contribui na omissão dos cidadãos no engajamento urbano é o constrangimento destes em situações públicas nos quais são requisitadas suas opiniões em audiências. Outro fator em destaque é a ausência de tempo para o comparecimento em encontros presenciais. 
O processo de participação social traz discussões exaltadas com tendências partidárias, fazendo com que os cidadãos se hostilizem e, automaticamente, se desencorajem. Ademais, tais métodos ${ }^{3}$ esmorecem os habitantes a "perderem seu tempo" em processos nos quais aparentam serem apenas protocolos necessários para os requisitos legais.

Desta forma, há a tendência do "comodismo" coletivo ao esperar dos profissionais envolvidos nos processos de solucionar os problemas da comunidade, evitando os debates e desqualificando a participação. Além disso, é necessário destacar que a própria comunidade não está acostumada em discutir e ter opiniões consolidadas sobre as questões debatidas, muito menos nos termos exigidos.

O processo participativo por si só exige lideranças, debates e negociações, e, tais questões muitas vezes entram em conflito com a dinâmica das comunidades. Reconhecer as dificuldades encaradas pelos mais pobres no processo participativo é o primeiro passo para a inclusão destes na dinâmica da cidade.

Da parte dos técnicos envolvidos, a necessidade de encaminhar uma relação com a população que se distancie da tradição de hierarquia e paternalismo exige uma reconfiguração de suas práticas e expectativas. Sem um enfrentamento teórico desta questão e sem uma etapa preliminar onde a população e a equipe técnica superem dificuldades intrínsecas ao processo, nenhum "convite" de participação será realmente eficaz (Nunes, 2016, p. 2).

Inicialmente, uma proposta à participação aos habitantes de uma cidade, principalmente quando esta é composta por uma população com altos níveis de pobreza e analfabetismo, como Salvador, são encontrados grandes obstáculos. A incapacidade de decisão desse grupo, já que possui baixa influência em seu meio (reforçado pelo poder econômico e social), contribui para que suas carências não sejam priorizadas.

A falta de conhecimento dos termos, ferramentas e fundamentos utilizadas pelos profissionais somadas ao despreparo relacionado às abordagens intensificam o sentimento de renúncia, obstaculizando mais ainda o processo de tomada de decisões (Nunes, 2016). A ausência de costume, iniciado desde a época escolar, acompanha-os desde cedo, provando a inexperiência diante a formalidade exigida da democracia direta.

Salvador, assim como outras cidades brasileiras, passa pelas conferências denominadas democráticas, mas que refletem apenas os interesses políticos do momento. A formação social da cidade (paternalista e autoritária) espelha a tradição centenária, servindo como insumo para retardar o avanço da democratização política (Campos, 2015).

\section{Análise da Aplicação da Escada de Participação Cidadã}

Necessitando de uma compreensão mais esclarecedora das nuances e potenciais de participação dos cidadãos, Sherry Arntein desenvolveu, em seu artigo destaque de 1969, a Escada de Participação Cidadã (Figura 1). Nele, ela explica seu conceito utilizando uma escada onde cada degrau concebe um estágio diferente de envolvimento da comunidade, além de que quanto mais se progride, mais poder é passado aos membros da comunidade no processo das ações públicas.

Para a autora, a redistribuição do poder que favorece aos cidadãos, hoje excluídos dos processos econômicos e políticos, a serem ativamente inseridos no futuro. Baseada na hierarquização de tipos de participação e não-participação, a autora elaborou uma tipologia de oito níveis da participação.

\footnotetext{
${ }^{3}$ Analisado por Paulo Freire (1979 e 1982) e Erving Goffman (1975), é intitulado por Nunes (1998) como "interiorização do estigma da pobreza", onde estuda a inferiorização da sociedade para com os pobres, fazendo-os com que desacreditem em seus potenciais tanto de forma individual quanto coletiva.
} 
Figura 1 - Oito degraus da Escada de Participação Cidadã.

\begin{tabular}{|r|l|l|}
\hline 8 & Controle cidadão & \multirow{2}{*}{ Níveis de poder cidadão } \\
\hline 7 & Delegação de poder & \\
\hline 6 & Parceria & \multirow{2}{*}{$\begin{array}{c}\text { Niveis de concessão } \\
\text { mínima de poder }\end{array}$} \\
\hline 5 & Pacificação & \\
\hline 4 & Consulta & \multirow{2}{*}{ Não participação } \\
\hline 3 & Informação & \\
\hline 1 & Terapia & \\
\hline 1 & Manipulação &
\end{tabular}

Fonte: Arnstein (1969). Desenvolvido pelas autoras.

Em analogia aos degraus de uma escada, sua base concebe zero oportunidade de participar, com degraus sucessivos representando ampliação dos níveis de participação até o controle total da tomada de decisão pelos cidadãos, quando ocorre a participação autêntica, segundo essa concepção.

Os dois primeiros degraus da escada consistem na Manipulação e Terapia. Eles representam a "não-participação", ou, uma participação seleta. Não tem como objetivo principal fazer com que os cidadãos de fato participem nas ações públicas ou privadas, mas sim a manipulação dos participantes. Nos degraus três e quatro (Informação e Consulta), os habitantes podem ouvir e serem ouvidos, mas não possuem o poder necessário para assegurar suas opiniões. Até este último é comum não haver progresso nos resultados obtidos pela população para melhorias na sua situação.

No degrau cinco, a Pacificação, representa a falsa participação dos cidadãos com o poder ainda retido nas mãos de uma minoria. Esses três degraus compreendem a "pouca concessão de poder". Em Sociedade (degrau 6) já é possível perceber algum nível de poder e controle dado aos cidadãos, onde o poder é dividido igualmente entre a comunidade e detentores de poder. Nos degraus 7 e 8 - Delegação de poder e Controle dos cidadãos - os cidadãos já possuem voz nas tomadas de decisões, quando não o poder administrativo completo. Desta maneira, os últimos três degraus finalizam a etapa "poder cidadão".

Aplicando a teoria da Escada de Arntein (1969) nas audiências públicas do PDDU de Salvador é possível identificar os estágios Informação e Consulta (degraus 3 e 4), onde os habitantes podem ouvir e serem ouvidos. No entanto, a ausência de meios para garantir sua opinião resulta na irrelevância dos detentores de poder aos pontos de vista em questão. Essa definição pode ser comprovada nas reclamações dos participantes no desrespeito dos acordos firmados entre os presentes nas audiências.

Essa realidade evidencia a importância de não negligenciar a participação social, principalmente por ser parte constituída da lei constitucional. O cotidiano é formado por atores sociais que fazem parte do meio, construindo suas percepções e vendo o poder não só como uma prática social histórica - ou seja, possuindo a distinção entre o centro e a periferia -, mas também, acima de tudo, uma relação de força.

\section{Conclusão}

Decerto, o Estatuto da Cidade veio com seus valores de justiça representando um marco crucial de transformações na conscientização da sociedade. Embora munido de instrumentos urbanos democráticos, sua aplicabilidade ainda é divergida por interesses específicos que insistem em se sobressair, evidenciando o obstáculo ainda a ser superado. 
Em Salvador não foi diferente. A participação de entidades específicas, sendo a maioria de cunho urbanístico, não retrata e nem representa a realidade soteropolitana, o que comprova um retrocesso na configuração político-institucional das organizações que representam a sociedade civil.

Vivemos em uma constante reprodução de sistemas de participação convencionais que não privilegia a classe baixa e ainda potencializa o desinteresse para o envolvimento dessas questões. A participação resulta em um ato não deliberativo, além de faltar representatividade nas audiências públicas.

Essas audiências públicas ainda são um mito de envolvimento social falho ao legitimar a opinião dos cidadãos. Os espaços cedidos não dão abertura a todos e, consequentemente, deixa de agir aos fatos e contribui para as omissões. O histórico da participação social reflete que a gestão democrática não consegue legitimar seus próprios valores, uma vez que para se contestar demanda poder e os envolvidos são escassos.

Todavia, não é uma tarefa fácil mudar costumes de anos. Para modificar os velhos hábitos é necessário mudar também os administradores e profissionais envolvidos no processo. Pessoas que encarem o exercício como um serviço à cidadania, que saibam lidar com o público e tenham a sensibilidade de identificar suas reais carências. Para que isso ocorra, se faz necessário a legitimação - antes de mais nada - das diferentes comunidades que compõem a imagem da cidade, para que assim seja possível o planejamento urbano específico e indispensável para cada espaço. Deste modo, a participação social será mais direcionada e efetiva, trazendo novos hábitos e resultados.

\section{Referências}

Arnstein, S. (1969). A Ladder of Citizen Participation. Journal of the American Institute of Planners. 35(4), 216-246.

Ancona, A. L. (2017). Zonas Especiais de Interesse Social - ZEIS. http://www.suelourbano.org/wp-content/uploads/2017/08/ANCONA-ZEIS-anexoSANTOS-JUNIOR-e-MONTANDON-planos-diretores-pos-estatuto-2011.pdf.

Arantes, O., Vainer, C. \& Maricato, E. (2000). A cidade do pensamento único. Ed. Vozes.

Bordenave, J., Díaz, E. (1994). O que é participação. Brasiliense.

Borges, S. S. (2015). Espaços políticos participativos: Caminhos e descaminhos da participação social nos conselhos municipais em Salvador, Bahia. 2015. Dissertação (Mestrado em Geografia) - Universidade Federal da Bahia, Salvador.

Brasil, A. (2016). A ineficácia das ZEIS: um problema de legislação ou uma questão polítco social? O caso de Fortaleza. Tese de doutorado do Programa de Pós-graduação em Arquitetura e Urbanismo da Universidade de São Paulo.

Brasil, Decreto $n^{\circ}$ 8.243, de 23 de maio de 2014. Institui a Política Nacional de Participação Social - PNPS e o Sistema Nacional de Participação Social SNPS, e dá outras providências. http://www.planalto.gov.br/ccivil_03/_Ato2011-2014/2014/Decreto/D8243.htm.

Bugs, G., \& Reis, A. T. L. (2014). Avaliação da participação popular na elaboração de planos de habitação de interesse social no Rio Grande do Sul. Urbe, Rev. Bras. Gest. Urbana. 2(6), 249-262.

Campos, C. M. (2015). Urbanismo e antiurbanismo no debate nacional. Estudos Avançados.

Fainstein, S. S. (2000). New directions in planning theory. Urban Affairs Review. 35(4), 451-478.

Ferrari Júnior, J. C. (2004). Limites e Potencialidades do Planejamento Urbano. Estudos Geográficos: Revista Eletrônica de Geografia. 1(2), 15-28.

Foucault, M. (1981). Microfísica do poder. Graal.

Gatti, S. F. (2015). Entre a permanência e o deslocamento. ZEIS 3 como instrumento para a manutenção da população de baixa renda em áreas centrais. O caso da ZEIS 3 C 016 (Sé) inserida no perímetro do Projeto Nova Luz. Tese de Doutorado. Universidade de São Paulo.

Hansen, H. S., \& Reinau, K. H. (2006). The Citizens in E-Participation. In: Wimmer, M. A. et al. (Ed.). EGOV 2006 - LNCS vol. 4084. Springer-Verlag, 7082.

Hermany, R., \& Frantz, D. (2010). A modernização da gestão pública municipal: uma perspectiva a partir das audiências públicas eletrônica. In: Leal, R. G.; REIS, J. R. (Orgs.). Direitos sociais e políticas públicas: desafios contemporâneos. Santa Cruz do Sul: Edunisc.

Manfredini, C., \& Lopes, J. R. (2005). Participação comunitária em projetos de desenvolvimento local: um estudo no bairro de Marins, Piquete/SP. In: Encontro Anual da ANPAD, 29. Anais... Anpad.

Medeiros, J. P., \& Borges, D. F. (2007). Participação cidadã no planejamento das ações da Emater - RN. 63-81. 
Research, Society and Development, v. 10, n. 9, e19310918046, 2021

(CC BY 4.0) | ISSN 2525-3409 | DOI: http://dx.doi.org/10.33448/rsd-v10i9.18046

Nunes, D. (2016). Participação Popular e Controle Social. Novos Paradigmas. https://www.novosparadigmas.org.br/wp-content/uploads/2016/12/Par ticipa\%C3\%A7\%C3\%A30\%20Popular\%20e\%20Controle\%20Social.pdf.

Pereira A. S. et al. (2018). Metodologia da pesquisa científica. UFSM.

Rolnik, R., Santoro, P. F. (2014). Zonas Especiais de Interesse Social (ZEIS) em Cidades Brasileiras: Trajetória Recente de Implementação de um Instrumento de Política Fundiária. Lincoln Institute of Land Policy, Estados Unidos da América.

Santos, M. (1996). A urbanização brasileira. Hucitec.

Secretaria Nacional de Habitação. (2009). Como delimitar e regulamentar Zonas Especiais de Interesse Social: ZEIS de Vazios Urbanos.

Silva, A. L. A., Machado, E. P., \& Siqueira, C. E. (2009). Melhor isso do que nada! Participação e responsabilização na gestão dos riscos do Pólo Petroquímico de Camaçari (BA). Ciênc. saúde coletiva. 6(14), 2153-2162.

Villaça, F. (2001). Espaço intra-urbano no Brasil. Studio Nobel. 